\title{
CONDIÇÕES SOCIAIS PARAA FORMAÇÃO DO CONHECIMENTO: COMO COMPREENDER O "FAZER CIENTÍFICO": CONSIDERAÇÕES SOBRE A POSIÇÃO EPISTEMOLÓGICA DE PIERRE BOURDIEU E JÜRGEN HABERMAS
}

\author{
THE KNOWLEDGE SOCIAL CONDICTTIONS: \\ UNDERSTANDING THE EPISTEMIC THINKING IN PIERRE \\ BOURDIEU AND JÜRGEN HABERMAS
}

Daniela Dias KunN ${ }^{1}$

Recebido em: 11/11/2011

Aprovado em: 12/07/2013

"Chegamos a saber que todo o indivíduo vive, de uma geração até a seguinte, numa determinada sociedade; que vive uma biografia e que vive dentro de uma sequência histórica. E pelo fato de viver, contribuir, por menos que seja, para o condicionamento dessa sociedade e para o curso de sua história, ao mesmo tempo é condicionado pela sociedade e pelo seu processo histórico". (C. Wright Mills em "A Imaginação Sociológica”)

RESUMO

O presente trabalho discute "o fazer científico" da Sociologia, indicando algumas modificações importantes na forma de construção do conhecimento. Nesse sentido, são apresentadas percepções de dois pesquisadores, Bourdieu e Habermas, os quais, partindo de bases epistemológicas diferentes, indicam que é preciso desacomodar os pesquisadores sociais da sua posição supostamente neutra em relação à produção do conhecimento. Dessa forma, ambos os pensadores são apresentados e, em seguida, confrontados em seu modo de fazer Ciência. Por vias, algumas vezes distintas, os autores concordam que um dos principais aspectos a ser definitivamente superado é a ideia de que o cientista social é independente do seu objeto de pesquisa; é, antes, constituído por ele, de uma forma ou de outra.

Palavras-chave: Construção do conhecimento; Bourdieu; Habermas.

\section{ABSTRACT}

This paper discusses the sociology "doing science". It indicates some important changes in the construction knowledge. This way, we present the perceptions of Bourdieu and Habermas. These scientists, starting from different epistemological bases, indicate us how it is necessary to take social researchers this supposedly neutral position (about the production of knowledge). Thus, both thinkers are presented and confronted in his way of doing science. With distinct ways, the authors agree in main aspect to be overcome: the idea that the social scientist is separated from the object of his search. Unlike, the social scientist is formed by them.

Keywords: Knowledge construction; Bourdieu; Habermas.

${ }^{1}$ Doutora em Desenvolvimento Rural pela Universidade Federal do Rio Grande do Sul (UFRGS), Brasil. Professora adjunta do Departamento de Economia da Universidade Federal de Santa Maria. E-mail: daniela.kuhn@ufrgs.br. 


\section{Introdução}

A discussão principal de que partem todos os grandes sociólogos do século XX, e que continua no século XXI, decorre da necessidade de tomada de uma posição em relação à articulação entre Estrutura e Ação. Isso significa dizer que está em discussão até que ponto o agente social - o indivíduo formador da sociedade - é capaz de articular seus interesses em relação às ações sociais ou em que medida esse agente é determinado pelas estruturas sociais que permeiam todas as tomadas de decisão ao longo da vida. É superada já a ideia de que as condições sociais dependem exclusivamente ou das ações dos agentes ou da conformação das estruturas que submete os agentes a determinados comportamentos.

A possibilidade de compreensão da Sociedade a partir da interação entre Estrutura/Ação permite perceber os mais diversos aspectos sociais que constantemente interagem entre si. Entre eles, como ocorre e como é possível a formação do conhecimento identificado com o adjetivo "científico"? O que significa "fazer Ciência" sob o ponto de vista dos sociólogos interessados em compreender as relações que constituem o mundo social?

Em reação ao positivismo lógico e ao funcionalismo, a sociologia contemporânea procurou aspectos capazes de conformar uma nova filosofia da Ciência, baseada, em um certo sentido, na reconstrução da história da ciência ou no "renascer" de uma dimensão hermenêutica do conhecimento. Este novo programa de investigação tentou identificar o papel ativo do investigador (de não meramente "observador imparcial") na produção científica.

Após um período histórico em que Religião e Ciência estiveram fortemente entrelaçadas, a sociedade parte em busca de uma separação definitiva entre esses aspectos. Esse processo histórico constitui-se a partir de uma série de princípios, que passaram a conceituar a noção de Ciência na Modernidade, dentre os quais é possível destacar a necessidade da "neutralidade" científica. Dessa maneira, a busca pela "verdade" em si. seria um processo, uma explicação que, a partir da utilização de um método (identificado, a partir daí, como método científico), seria capaz de apresentar a realidade como a partir de um conjunto de premissas associadas a determinado experimento. A busca pelo processo de construção de "uma verdade", constitui em si mesma um ato político de vontade. Esse processo, reproduzido amplamente, até pouco tempo atrás, de forma homogênea (e ressaltese, seguido até hoje por um grupo, cada vez menor, de cientistas), levou à necessidade de separar o pesquisador de seu objeto. A partir de então, apenas os fatos reproduzíveis poderiam ser chamados de Ciência. Esse padrão de geração de conhecimento, obviamente, como cotidianamente é possível perceber, levou a um crescimento econômico importante em todo o planeta e a uma organização política que acentua as desigualdades sociais.

É interessante observar que essa forma "neutra" de fazer Ciência surge em um momento em que o processo de criação e explicação do mundo estava, em alguma medida, obscurecido por comportamentos religiosos que monopolizavam o conhecimento gerado. Sendo assim, o positivismo cumpre com a função de rompimento entre Ciência e Religião, mas, nessa busca por neutralidade, não é capaz de explicar fenômenos sociais, demasiadamente complexos para submeterem-se a explicações "neutras" e "segmentadas".

Na medida em que há um esgotamento das possibilidades de leituras do mundo, a partir da utilização do método científico (em que a máxima pode ser traduzida como "o todo é representado pela soma das partes"), uma série de cientistas, das mais diferentes áreas, passa a questionar essa noção de neu- 
tralidade, que durante muito tempo norteou o fazer científico.

Entre os críticos do positivismo, que abrangem diversas percepções em relação à constituição social da Ciência, encontram-se Pierre Bourdieu e Jürgen Habermas. Nesse sentido, o objetivo deste breve trabalho é identificar, nos posicionamentos desses dois sociólogos contemporâneos, aspectos fundamentais para a constituição de um fazer científico consciente em relação às suas limitações e possibilidades.

Bourdieu sugere uma ruptura da Ciência com os fenômenos naturalizados a partir das relações cotidianas e procura identificar o processo de possibilidade de reflexividade da ciência na determinação do "fazer científico". O sociólogo francês, na tentativa de compreender a formação do "campo" e do habitus do cientista - que reflete a lógica de atuação estratégica do ser social dedicado ao exercício escolástico -, localiza-se em um lugar de enunciação externo ao objeto de análise. Ainda que muitos críticos possam reconhecer nele um "olhar quase que divino/profeta", não se pode negar que a concepção teórica desenvolvida por Bourdieu permite a identificação de diversos aspectos latentes que, a outros "olhares", ficariam sem questionamentos e naturalizados na prática do saber científico.

A mesma tentativa de "desmascaramento" do cientificismo é feita por Habermas, porém, a partir de uma perspectiva interna da prática científica, procurando identificar o cientista como um ser social que faz ciência e percebe o mundo estando mergulhado nas tradições do próprio contexto social. A proposta do autor para a compreensão do processo de produção do conhecimento está baseada em um procedimento hermenêutico de reconstruções lógicas e empíricas em relação ao que pode ser identificado como Ciência.

Partindo dessa rápida introdução, este trabalho apresenta-se divido em três seções, além da introdução e das considerações finais. A primeira seção apresenta a percepção de Bourdieu em relação à formação do conhecimento. Em seguida, são apresentadas algumas considerações, no mesmo sentido, de acordo com a teoria sugerida por Habermas. Na terceira seção é realizado o esforço de identificar os aspectos em relação aos quais os autores divergem e aqueles pontos em que é possível identificar a coexistência entre as duas formas de concepção quanto ao "fazer científico", ao analista social e ao objeto de estudo.

Certamente, não há porque imaginar que um breve trabalho como este poderia exaurir a discussão sobre a formação do conhecimento e, menos ainda, sobre a possibilidade de debate entre esses dois importantes autores da sociologia contemporânea. Entretanto, o trabalho evidencia as estruturas diferenciadas de pensamento em relação à formação daquilo que atualmente é reconhecido de modo natural ${ }^{2}$ como campo científico. Sendo assim, espera-se que, com a ainda incipiente análise, seja possível chamar atenção para a possibilidade de pensar a Ciência e evidenciar seus interesses com base em uma noção capaz de desnaturalizar a constituição do conhecimento científico, que ainda é adjetivada e defendida como "neutra" por uma quantidade representativa de cientistas que, a partir desta confortável situação, fogem a uma profunda discussão sobre a constituição de tudo o que é legitimado sob o adjetivo científico.

\section{Bourdieu: a constituição histórica do conhecimento científico}

A maneira de pensar as relações sociais sugeridas por Bourdieu é, muitas vezes, confundida com a "vitória" da estrutura a que os indivíduos estão imersos no contexto social sobre as possibilidades de ações autônomas desses mesmos indivíduos (ao tentar localizar

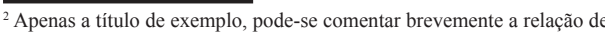
gênero e a sequência de tempo (dia/Sol-masculino; noite/Lua-feminino). 
as posições em relação à suposta dicotomia entre Estrutura/Ação). Bourdieu colocou em pauta o reconhecimento do papel das estruturas e a sua identificação (essencialmente pelo questionamento da neutralidade científica) para compreender como as relações sociais ocorrem a partir destas, em certa medida, determinadas e limitadas por condições estruturais naturalizadas cotidianamente $^{3}$. O autor salienta que o limite do que é chamado de pensamento escolástico está intimamente relacionado às condições históricas que conformaram a emergência da própria possibilidade de existência desse pensamento enquanto espaço com autonomia para discutir determinados aspectos da realidade social.

A verificação da construção dos aspectos naturalizados dentro de cada campo do conhecimento e o questionamento deste permitiriam a constatação do que realmente está em jogo. Sem o objetivo de modificar a realidade social, e, sim, com o de compreender seus mecanismos estratégicos, o autor inseriu conceitos abstratos (e que precisam ser questionados e construídos em cada caso de análise) como: habitus, doxa e campo. A partir desses conceitos, Bourdieu explica o processo de formação e mudança dos ambientes de relações sociais que refletem certa hierarquia de poder, que, ao fim e ao cabo, submete aqueles que tem pouco capital (dos diversos tipos caracterizados por Bourdieu) aos que são capazes (por si sós ou devido à inserção em determinadas estruturas - o que está correlacionado fortemente às trajetórias de vida dos atores sociais) de acumular capitais valorizados socialmente. Na obra específica dedicada à análise do campo escolástico, Bourdieu indica claramente que é preciso tentar fugir da ilusão de uma Ciência neutra e detentora da possibilidade de encontrar a verdade:

Creio que, antes de tudo, convém refletir tanto acerca dos limites do pen-

3 "Trata-se apenas de tentar determinar se (e em que) ela [condição social] afeta o pensamento que ela própria torna possível e, daí, a forma e o conteúdo próprio do que pensamos" (BOURDIEU, 2001. P.61). samento e dos poderes do pensamento, como a respeito das condições de seu exercício que levam tantos pensadores a ultrapassar os limites de uma experiência social forçosamente parcial e local, geográfica e socialmente, circunscrita a um pequeno cantão, sempre o mesmo universo social, e até intelectual, tal como demonstra a estreiteza das referências invocadas muitas vezes reduzidas a uma disciplina e a uma tradição nacional. A observação atenta do movimento do mundo deveria, no entanto instigar mais humildade, quando se sabe que os poderes intelectuais são tanto mais eficazes quando se exercem no sentido das tendências imanentes da ordem social, redobrando então, de maneira indiscutível, pela omissão ou pelo compromisso, os efeitos da força do mundo, as quais também se expressam por seu intermédio (BOURDIEU, 2001, p.11, grifo do autor).

A questão principal da teoria "bourdiana" abrange a irracionalidade (no sentido de ausência de consciência) da ação dos indivíduos. Isso significa que os agentes sociais estão inseridos em uma racionalidade estrutural que não é questionada, que é aceita como "algo natural" pela sociedade em geral. Entretanto, o autor demonstra que em vários aspectos as categorias aceitas como "naturais" são constituídas historicamente e naturalizadas a partir da valorização e da imposição de interesses específicos. Tal posicionamento reflete a necessidade de conscientização de que essas categorias são, na realidade e na maioria das vezes, ordenadas e constituídas contra aquilo que poderia ser a vontade dos indivíduos, a percepção de cada um em relação ao que seria preferível.

Partindo de uma relação estabelecida e delimitada pela constituição de um poder simbólico, ou seja, a constituição de um poder invisível/estrutural que condiciona a ação dos indivíduos e só pode ser exercido a partir da cumplicidade entre os controlados.Bourdieu procura determinar a constituição da 
sua autonomia e o seu processo de legitimação também para o campo científico. Assim como os outros campos (artístico, religioso, político, econômico, por exemplo), o campo científico afirma-se a partir de um fim específico que se configura com o objetivo de fazer sentido tanto interna como externamente ao campo.

Para analisar o campo escolástico, Bourdieu utiliza seus conceitos de habitus (a percepção da estrutura da lógica de ação específica da escolástica) e de doxa (a lei incontestada e própria desse campo, ou seja, o conjunto das crenças fundamentais que não tem sequer necessidade de se afirmar sob a forma de um dogma explícito - aquilo que é naturalizado dentro do campo). A adesão à doxa pressupõe o compartilhamento dos interesses que estão em jogo, a que Bourdieu chama de illusio. A illusio é "a crença fundamental no interesse do jogo e no valor dos móveis de competição inerente a esse envolvimento" (BOURDIEU, 2001, p. 21).

\begin{abstract}
A lógica específica de um campo se institui em estado incorporado sob a forma de um habitus específico, ou melhor, de um sentido do jogo, ordinariamente designado como um 'espírito' ou um 'sentido' ('filosófico', 'literário', 'artístico' etc.), que praticamente jamais é posto ou imposto de maneira explícita (BOURDIEU, 2001, p. 21, grifo do autor).
\end{abstract}

A partir de uma percepção em relação à temporalidade de produção nos campos, Bourdieu chama a atenção à necessidade de uma contínua expulsão para o passado daqueles que já foram em outro momento a vanguarda, devido ao surgimento de novos espaços para as possibilidades que vem sendo abertas no campo científico. Essa compreensão evidencia que Bourdieu não pode ser acusado de ser um autor determinista que dá à estrutura todo o poder de moldar os indivíduos, pois, ainda que as transformações e a possibilidade da mudança ocorram dentro do espaço de possíveis configurado pela própria estrutura, há, sim, uma ação que acabará por alterar as características estruturais do campo em questão.

A cada momento do tempo, em um campo de lutas qualquer que seja (campo social em seu conjunto, campo do poder, campo de produção cultural, campo literário etc.), os agentes e as instituições empenhados no jogo são a uma só vez contemporâneos e temporalmente discordantes. O campo do presente não é mais que outro nome do campo de lutas. A contemporaneidade como presença no mesmo presente existe praticamente apenas na luta que sincroniza tempos discordantes ou, melhor, agentes e instituições separadas por tempo e na relação com o tempo: uns, que se situam além do presente, têm contemporâneos que reconhecem e que os reconhecem apenas entre os outros produtores de vanguarda e têm público apenas no futuro: os outros, tradicionalistas ou conservadores, não reconhecem seus contemporâneos senão no passado (BOURDIEU, 1996,p. 183, grifo do autor).

Assim, essa lógica de mudança permite que determinadas percepções sejam superadas por outras não de um dia para o outro, mas através de um processo de lutas históricas que levam algum tempo. Através da familiarização dos agentes sociais com a nova proposta estrutural, há uma tendência de que a nova percepção banalize-se até assumir completamente o lugar da anterior e torne-se ela mesma "alvo" das novas vanguardas (literária, científica etc.).

O campo escolástico, assim como o artístico, pretende uma diferenciação em relação ao campo econômico, pois os agentes desses campos estariam procurando afastar-se dos problemas imediatos, simulando desinteresse (que, na verdade, é interessado, como nos alerta Bourdieu, na medida em que foi construído e aceito historicamente) em rela- 
ção à possibilidade de receber recompensas econômicas. Há, inclusive, uma valorização daqueles que demonstram preocupação com a coerção da economia em relação ao campo. Segundo o próprio Bourdieu (2001, p. 24):

A situação escolástica é um lugar e um momento de leveza social onde [...], pode-se 'jogar seriamente', [...] levar a sério disputas lúdicas, ocuparse seriamente de questões ignoradas por pessoas sérias, simplesmente envolvidas e preocupadas com as questões práticas da existência ordinária.

$\mathrm{Na}$ tentativa de revelar a conformação do universo escolástico, o autor francês descreve importantes mecanismos naturalizados de seleção daqueles que seriam reconhecidos como detentores da possibilidade de fazer Ciência. Esses mecanismos seriam originários dos próprios procedimentos escolares, desde a infância de cada um ${ }^{4}$. A partir da estrutura a que todos os indivíduos estão submetidos nos bancos escolares, seria feita a diferenciação entre os excluídos e os escolhidos. Tal diferenciação parece ser a gênese da divisão de trabalho, refletida na hierarquização profissional na vida adulta. É preciso reconhecer que a liberdade intelectual, é limitada por condições estruturais que, ao serem conhecidas, podem ser superadas (BOURDIEU, 2001).

Segundo o autor, o cientista precisa diferenciar-se claramente do "homem comum". Essas duas construções sociais são aceitas naturalmente e seriam essenciais para a legitimação da ciência enquanto informação autônoma e confiável. Quando um indivíduo assume determinado papel dentro da estru-

\footnotetext{
4 "Aqueles imersos, alguns desde o nascimento, em universos escolásticos constituídos ao cabo de um longo processo de autonomização tendem a esquecer das condições históricas e sociais de exceção que tornam possível uma visão do mundo e das obras culturais orientadas pelo signo da evidência e do natural. A adesão encantada ao ponto de vista escolástico se enráza no sentimento próprio das elites escolares, do eleic̃o natura se en pelo don; e un dos efeitos procenta res de formação e seleção, operando como ritos de instituição consiste em instaurar uma fronteira mágica entre os eleitos e os excluídos, garantindo ao mesmo tempo o recalque das diferenças de condição que, como se consagram" (BOURDIEU, 2001, p. 35-36)
}

tura social, os caminhos já estão mais ou menos definidos (BOURDIEU, 2001). Para Bourdieu, cientistas, especialmente aqueles considerados os "grandes iniciados", estão tão convencidos da $\mathrm{il}$ lusio e aderem tão fortemente à doxa do campo escolástico que, segundo a percepção bourdiana, não realizam escolhas com autonomia. "Para que façam uma boa escolha" (BOURDIEU, 2001, p. 48), eles teriam de estar tão transpassados pela atuação do campo que não seriam capazes de perceber que seus "sucessos profissionais" podem simplesmente representar não sua "genialidade exclusiva" naquele espaço, mas exatamente o contrário, que ele pode ser substituído por qualquer outro escolhido que se adapte e assuma a doxa do campo escolástico de maneira completa, sem querer "escapar" da sua racionalidade estratégica. O reconhecimento de um agente dentro do campo escolástico reflete uma "solidariedade" combinada, respaldada pelo habitus deste grupo social que acaba por consolidar-se como um grupo homogêneo. Pode-se perceber também a existência de uma persuasão discursiva, deles e para eles, sobre a impossibilidade de substituição de cada um. Esse compartilhar da crença é explicado por Bourdieu (2001, p. 54):

Os efeitos do internamento escolástico, redobrados pelos da eleição escolar e da coabitação prolongada de um grupo socialmente muito homogêneo, acabam favorecendo uma distância intelectual em relação ao mundo: paradoxalmente, o corte social e mental se manifesta, sobretudo, nas tentativas, por vezes patéticas e efêmeras, para recontatar o mundo rela, mormente através de engajamentos políticos (estalinismo, maoísmo etc.) cujo utopismo irresponsável e cuja radicalidade irrealista atestam o quanto são ainda uma maneira de negar as realidades do mundo social.

Bourdieu, de certa forma, procura colocar-se como um observador privile- 
giado, empreendendo, como cientista (sociólogo), um exercício de se colocar de fora do campo científico para o analisar. Assim, o autor define a vigilância epistemológica como a condição essencial para a ruptura com o processo de naturalização das configurações sociais, neste caso do próprio campo escolástico - a que, em certo sentido, foi submetido e submeteu-se. Atentando para a peculiaridade do campo escolástico, no qual o autor procura seu espaço de legitimação, Bourdieu indica que o resultado desta configuração social permite a reprodução e a produção de um conhecimento dito e legitimado como científico, apesar de ser produzido a partir de uma construção histórica de lutas que é aceita como uma evolução da construção do saber científico. Entretanto, esse resultado, em termos de capital, só é reconhecido como poder se está inserido e serve a uma rede de poder. Ainda que essa possa parecer uma distinção irrelevante, é preciso salientar que esse conhecimento necessita da aprovação desse poder invisível/simbólico, ou não é científico (não são poucos os exemplos de conhecimentos que não são considerados científicos, muitas vezes por ameaçar espaços da Ciência atualmente consolidada, por exemplo, os mais diversos ramos da chamada medicina alternativa). É sempre preciso atentar também para as condições socioeconômicas que permitem a emergência de determinadas análises dentro do campo escolástico $^{5}$, o que significaria analisar as condições políticas próprias para a reprodução do conhecimento científico

${ }^{5}$ Segundo Bourdieu: "Tendo podido libertar-se aos poucos das preocupações materiais imediatas, graças, sobretudo aos benefícios proporcionados pela venda direta ou indireta de conhecimentos práticos aos empreendimentos mercantis ou ao Estado, e acumular, pelo e para o trabalho, aptidões (de início adquiridas na escola) tendentes a funcionar como capital cultura, esses novos agentes sociais se mostraram inclinados e capazes de afirmar sua autonomia individual e coletiva perante os poderes econômicos e políticos que tinham necessidade de seus serviços" (2001, p. 31). Ainda: "Se não há dúvida de que a orientação e a forma da mudança dependem do 'estado do sistema', ou seja, do repertório de possibilidades atuais e virtuais oferecido, em um momento dado, pelo espaço das tomadas de posições culturais (obras, escolas, figuras exemplares, gênero e formas disponíveis etc), elas dependem também e, sobretudo das relações de força simbólicas entre os agentes e as instituições que, tendo interesses inteiramente vitais nas possibilidades propostas como instrumentos e apostas de luta, aplicamse, com todos os poderes de que dispõem, em fazer passar ao ato aquelas que lhes parecem mais de acordo com suas intenções e seus interesses específicos" (BOURDIEU, 1996, p. 230) reconhecido, algo que está fora do escopo deste trabalho.

Por fim, é preciso reconhecer que a forma de pensar e reconstruir as realidades sociais proposta por Bourdieu é inovadora, pois procura identificar e tornar claro, aspectos que foram construídos social e historicamente para figurarem como relações sociais naturais. A proposta de um exercício de reconstrução do espaço abstrato, permite o reconhecimento das relações de poder que limitam as possibilidades de ação do próprio fazer científico. Ainda que claramente não exista, nessa abordagem teórica, uma intenção de alterar as condições sociais, própria de outros autores como o Habermas, é preciso reconhecer os resultados que essa agenda de pesquisa apresenta (além de possibilidades interessantes de reflexão pessoal sobre os papéis sociais atribuídos e assumidos por cada indivíduo), como as novas questões e os novos objetos de pesquisa que, até então, não eram problematizados. Segundo o próprio autor, "sob as aparências mais triviais, quais sejam as da banalidade cotidiana, (...) o mundo social esconde as revelações mais inesperadas sobre o que menos queremos saber acerca de quem somos" (BOURDIEU, 2001, p. 18).

\section{Habermas: o conhecimento como interesse}

Enquanto Bourdieu procura associar o limite da razão escolástica e da formação do conhecimento às possibilidades estruturais a que cada agente social tem acesso, Habermas reflete sobre a possibilidade de uma retomada da autonomia do sujeito. Se, por um lado, Bourdieu crê na importância decisiva das estruturas para a configuração do conhecimento, Habermas resolve a tensão Estrutura/Ação considerando o papel fundamental da racionalidade do sujeito e de suas possibilidades de ação. De forma simplista, é possível afirmar que onde Bourdieu encontra os limites 
do conhecimento científico Habermas identifica suas possibilidades de avanço em prol de uma melhoria da vida em sociedade. No pensamento habermasiano, há um espaço de autonomia dos atores sociais, ainda que não sejam negligenciados os processos de condicionamento e de coerção impostos aos agentes pelas estruturas sociais.

A concepção de Ciência apresentada por Habermas, que também procura negar a positivismo como forma de perceber as relações sociais, é definida como um processo de racionalização crescente, no sentido de que há uma possibilidade de percepção evolutiva em relação ao conhecimento científico em direção a determinada situação ideal de comunicação entre os sistemas sociais. Com um arcabouço teórico próprio e diferente dos termos e conceitos desenvolvidos por Bourdieu, Habermas apresenta a sociedade composta por sistemas que interagem através de processos comunicativos que tendem, a partir do interesse no estabelecimento de consensos, a proporcionar um mundo melhor a todos, mais justo, de acordo com a concepção de justiça desenvolvido por John Ra$\left.w^{6} s^{6}\right)$. Com base nessa ideia de justiça, Habermas abre caminho para um agir a partir da produção do conhecimento.

Diferentemente de Bourdieu, o programa de pesquisa do autor alemão considera o pesquisador imerso em um mundo social e que, por isso, reflete conformações desse mundo e é influenciado por ele. Nesse sentido, o cientista não assume um papel externo ao objeto de análise (no caso, o processo históri-

\footnotetext{
${ }^{6}$ Segundo Oliveira (2003, p. 18), em uma obra sobre John Rawls: "Através de dois princípios de justiça deve ser efetivada a distribuição eqüitativa de bens primários (primary goods), isto é, bens básicos para todas as pessoas independentemente de seus projetos pessoais de vida ou de suas concepções do bem. Rawls freqüentemente enfatiza que os mais fundamentais de todos os bens primários são o auto-respeito (self-respect) e a auto-estima (self-esteem), acompanhados das liberdades básicas, rendas e direitos a recursos sociais como a educação e saúde. Os dois princípios são enunciados da seguinte maneira: Primeiro: Todas as pessoas têm igual direito a um projeto inteiramente satisfatório de direitos e liberdades básicas iguais para todos, projeto este compatível com todos os demais; e, nesse projeto, as liberdades políticas, e somente estas, deverão demais; e, nesse projeto, as liberdades politicas, e somente estas, deverão
ter seu valor eqüitativo garantido. Segundo: As desigualdades sociais e econômicas devem satisfazer dois requisitos: (a) devem estar vinculadas a posições e cargos abertos a todos, em condições de igualdade eqüitativa de oportunidades; e (b) devem representar o maior benefício possível aos membros menos privilegiados da sociedade".
}

co de formação do conhecimento), mas analisa-o a partir de sua própria vivência e de seus interesses ${ }^{7}$. Declara Habermas (1982, p. 325): “(... eu apenas afirmo que a auto-reflexão ${ }^{\overline{8}}$ bem-sucedida é novamente reabsorvida pelo processo de formação que se faz consciente".

A partir de uma aproximação com Freud (que mune Habermas de instrumentos que "desmascaram" os interesses naturalizados a partir das relações sociais), o autor desenvolve uma teoria que busca revelar os interesses cognitivos que levam à ação dos indivíduos. Essa noção indica que a produção do conhecimento não é possível sem uma ligação com o interesse humano. Assim, o autor questiona fortemente em que medida é possível pensar em uma ciência neutra (seja ela pertencente às ciências sociais ou às naturais). A sugestão apontada por Habermas é desenvolver um método de conhecimento hermenêutico que possibilite uma constante avaliação para estar "evoluindo" em direção de um interesse comunicativo. Esse entendimento mútuo, a partir de uma noção de conhecimento como interesse, é o elemento fundamental da sua Teoria do Agir Comunicativo, que apresenta a concepção de análise, avaliação e possível intervenção do cientista social no mundo real.

Sendo assim, a Ciência é possível a partir de aspectos fundamentais das relações sociais no mundo real: a) a linguagem - caracterizada como a comunicação entre os diferentes; b) o trabalho - que é a transformação da natureza para a autossatisfação para a satisfação dos interesses humanos; e c) a interação social - espaço de compreensão do outro, da percepção do concorrente.

Ao evidenciar a possibilidade de comunicação para a compreensão do

\footnotetext{
7 "The sciences have retained one characteristic of philosophy: the illusion of pure theory. This illusion does no determine the practice of scientific research but only its self-understanding. And to the extent that this self-understanding reacts back upon scientific practice, it even has its point" (HABERMAS, Knowledge and human interests apud OUTHits point" (HABTE, 1996)

${ }^{8}$ Ainda na mesma obra, Habermas (1982, p. 331) define o que está sendo entendido como autorreflexão: "Auto-reflexão significa o esclarecimento e a remoção analítica dos pseudo-apriori, próprios aos limites perceptivos e às compulsões acionais cujas motivações se localizam no inconsciente".
} 
processo do conhecimento, Habermas admite uma questão prática que acaba por anteceder o conhecimento científico. Ao invés de investigar o que leva à formação e à possibilidade de emergência de determinada questão, o autor já parte do que está estabelecido (similar ao que Bourdieu chama de campo científico) para uma reconstrução empírica do processo de conhecimento que tem condições de evoluir a partir dessa constituição do objeto possível ${ }^{9}$.

$\mathrm{Na}$ tentativa de construir um arcabouço teórico capaz de compreender esse processo, o autor discute e relação entre objetividade e verdade. Para explicar a formação do conhecimento, a partir de uma noção de interesse que está relacionada à experiência pessoal e à capacidade de formação de discurso e de validade argumentativa, Habermas (1982, p. 333) considera que:

O sentido categorial de um enunciado empírico determina-se de acordo com a estrutura da área do objeto, à qual este enunciado se refere. Tal sentido constitui-se com os objetos da experiência possível, isto é, tratase do a priori material da experiência sob o qual a descobrimos a realidade no exato momento em que a objetivamos. Deste sentido distingui-se o sentido discursivamente conversivel da reivindicação pela validade; um sentido que comprometemos, implicitamente, com cada asserção que fazemos. O sentido, no qual uma proposição pode ser verdadeira ou falsa, não consiste nas condições da objetividade da experiência mas, sim, na possibilidade de fundamentar, em termos argumentativos, um posicionamento que, reivindicando validade, é também passível de crítica. O sentido categorial de enunciados reporta-se ao gênero dos objetos da experiência, dos quais afirmamos algo; o sentido inerente à pretensão de afirmar, no discurso, algo de válido, refere-se à existência de estados determinados

${ }^{9}$ Conforme Outhwaite (1994, p. 25), "the hermeneutic process is not the replacement of the interpreter's horizon' by that of the object is study, but a dialogical process in which the two horizons are fused together". de coisas, esses aos quais voltamos a dar existência pelas asserções que acerca deles fazemos. O sentido categorial está contido no conteúdo intencional de um ato lingüístico, a reivindicação pela validade na parte performativa do mesmo ato" (Grifo do autor).

Nesse sentido, o autor procura enfatizar como a formação do conhecimento é tematizada pela experiência daqueles que pretendem validar determinada informação, reconhecida como científica. A escolha por determinados problemas e programas de pesquisa está recorrentemente sendo avaliada pela percepção da capacidade discursiva do cientista. Entretanto, a validação só é corroborada no plano argumentativo, em que o discurso é apenas um recurso para a argumentação.

O objetivo cognitivo de processos discursivos de formação da vontade localiza-se no consenso obtido por argumentação, tendo por base a capacidade de generalização de interesses propostos durante o discurso (HABERMAS, 1982, p. 347).

A reivindicação científica de determinado fato é realizada de experimentos, que, por meio da organização dos dados e da análise dos resultados, servem como recurso argumentativo no reconhecimento de determinada asserção como válida, a partir da comprovação da hipótese pelos dados. ${ }^{10}$. $\mathrm{O}$ experimento objetivo é uma possibilidade de interpretação da realidade, resultado da percepção do agente, a partir de seus interesses. Quando discute Ciência, Habermas está imerso na discussão da Academia Alemã interessada em entender o processo emancipatório do agente social e, além de propor uma possibilidade de análise para a formação do conhecimen-

\footnotetext{
10 “(...) a objetividade de uma experiência significa que cada qual pode contar com o sucesso ou o insucesso de determinadas ações; a verdad de uma proposição, feita no medium do discurso, significa que cada um pode ser levado, desde que haja razões para tanto, a reconhecer como justificada a reivindicação de uma asserção que pretende ser válida" (HABERMAS, 1982, p. 337, grifos do autor).
} 
to, demonstra, através de seus escritos, interesse em desfazer a noção de uma ciência neutra e em discutir a separação (quase dicotômica) existente entre ciências sociais e ciências naturais.

Além disso, conforme já foi comentado, o autor refere-se a um interesse emancipatório que, através da formação do conhecimento, fundamentaria a ação no mundo real, em direção a uma sociedade mais justa. O rompimento com o "a priori" das Ciências levaria a essa possibilidade de emancipação e a uma capacidade de compreensão mais complexa da realidade social.

Nessa concepção, o progresso tecnológico é considerado como um instrumento importante, que permite a validação (via controle de experimentos) das explicações teóricas capazes de interpretar "de forma sempre mais adequada à área de objeto constituída à moda pré-científica" (HABERMAS, 1982, p. 351). O progresso científico e as alterações na interpretação da linguagem permitem que se constitua não novos exemplos das mesmas experiências, mas a produção de novas experiências para obtenção e modificação das condições de aceitação para as pretensões de validade sugeridas.

É importante, por fim, considerar a concepção habermasiana da Ciência como uma nova possibilidade de analisar a formação do conhecimento científico, a partir de uma posição que surge para se contrapor ao positivismo. Entretanto, para Habermas, os fatores principais não são necessariamente as estruturas sociais que levam os atores sociais à proposição de determinados problemas de pesquisa, mas, sim, como, a partir desses problemas, é possível perceber os interesses e, em certo sentido, corrigi-los, promovendo uma evolução no pensamento social. A maior autonomia dada ao cientista, ao agente social, possibilita um "pensar o mundo" talvez menos determinista do que aquele dominado pela "ilusão da escolha"11. Ha-

Habermas enfatiza, em sua obra, especialmente em relação à análise bermas indica que sua tentativa de compreender a formação do conhecimento científico é feita através da percepção dos interesses envolvidos:

Ocorre que introduzo interesses orientadores de conhecimento com o objetivo de explicar o elo objetivo entre fatos que dependem do discurso e áreas de objeto constituídas de maneira pré-científica. A construção de interesses do conhecimento deve tornar compreensível a inserção sistemática, ainda que condicional, do saber teórico, engendrado discursivamente na práxis da vida, inerente a uma forma de vida passível apenas de reprodução por meio de declarações suscetíveis de ser verdadeiras (HABERMAS, 1982, p. 351).

\section{Bourdieu e Habermas: enfim, seme- lhanças e diferenças}

O ponto de partida para a sugestão desta discussão acerca desses dois importantes cientistas sociais, Habermas e Bourdieu, tem um ponto básico em comum: ambos buscam a desconstrução da forma de "fazer Ciência" incorporada, e não questionada, pela sociedade moderna com a implantação do positivismo. A complexidade da sociedade atual exige um pensamento social que, além de perceber claramente homogeneidades - traço primordial do positivismo - seja capaz de incorporar a diversidade em suas forma de análise (tratando essa diversidade como erro, em termos estatísticos, ou como algum tipo de anomalia social). Nesse sentido, ambos os autores consideram a necessidade de repensar o modo de construção do saber científico legitimado socialmente. $\mathrm{O}$ esforço passa, nas duas formas de avaliação, por uma percepção da origem do problema a ser tratado, ou seja, por uma desnaturalização do interesse político e econômico que se esconde sob a "neutralidade" científica.

das consequências de um possível agir comunicativo, o que chama de "ilusão de participação". Sendo assim, o agente social teria autonomia para em determinado momento "perceber por si" essa ilusão e os condicionantes dela 
Apesar de os autores identificarem essa análise do modo como se faz Ciência, suas propostas de desvelamento/conscientização são diferentes. Para Bourdieu, há um processo constante de disputa de forças políticas e econômicas. $\mathrm{O}$ próprio autor apresenta alguns momentos em que esse processo foi desvelado em alguns campos, entretanto o campo escolástico não conseguiu ainda se reconstruir. Esse processo passa invariavelmente por uma ruptura, em que ocorre a reorganização do campo, bem como das suas forças e de seus atores sociais. Imagina-se, pela concepção de Bourdieu, que seja possível, ao menos teoricamente, alterar o comportamento dos agentes sociais dentro do campo, entretanto, seria sempre necessário que a sociedade estivesse atenta a que tipo de poder as "novas regras" estariam subordinadas. A construção da nova estrutura é feita com base em uma ruptura do poder, há uma troca de interesses dentro do campo. Nesse sentido, há uma discussão em relação à possibilidade de autonomia do agente social em Bourdieu, o que ocorre, teoricamente, é uma troca de força dentro do campo.

Assim como Bourdieu, Habermas incorpora a formação do conhecimento à sua proposta de compreensão do modo de pensar o mundo de uma maneira geral. O conhecimento é validado a partir de uma prática argumentativa que é aceita com a pressuposição de um consenso que o legitime. "A única coerção permitida nos discursos é aquela do melhor argumento; o único motivo admitido é aquele da procura cooperativa da verdade" (HABERMAS, 1982, p. 335).

Enquanto Bourdieu afirma que o papel do cientista social é o de analisar a realidade para a compreender melhor, o autor alemão dá "o passo seguinte" e propõe a possibilidade de intervenção na realidade analisada, a partir de alguns parâmetros (como, por exemplo, o de justiça já apresentado). Habermas considera que, partindo da compreensão das forças argumentativas, é possí- vel chegar a um consenso que permite não apenas uma troca de forças, mas um avanço social efetivo, no que tange ao objetivo de uma sociedade mais justa.

Dessa forma, em termos de diferenças, pode-se destacar que para Bourdieu não há um plano normativo para a atuação, enquanto para Habermas essa percepção é parte da busca por uma sociedade mais justa. Distinguem-se, aí, claramente, duas escolas de pensamento: uma que percebe a realidade em que está imersa e outra que propõe uma nova sociedade. Implícito a isso, volta-se a questão fundamental, o que é mais determinante para a formação do conhecimento, a Estrutura ou a Ação?

\section{Considerações finais}

A questão fundamental que inquieta mais de uma geração de sociólogos do século XX, ainda não foi equacionada. $\mathrm{O}$ que pode ser considerado determinante: $\mathrm{o}$ aspecto estrutural a que a sociedade, bem como a reprodução, está submetida ou a possibilidade ilimitada de ação do indivíduo para a transformação social? Certamente esta não é uma resposta fácil nem única; é preciso ponderar sobre essas possibilidades. Uma sociedade determinada unicamente pelas estruturas estaria condenada a permanecer sempre da mesma forma (ou com progressos que invariavelmente reproduzissem as condições estruturais dadas em determinado momento). A realidade evidencia que, com o passar do tempo ${ }^{12}$, os progressos, além de muitas vezes não colaborarem com a reprodução das estruturas, acabam por suprimir ou substituir tais condições.

Entretanto, não se pode negar que as escolhas e as possibilidades de atuação dos atores no ambiente social não são totalmente aleatórias. Há uma conformação histórica e social que acaba por ter um importante papel na de-

\footnotetext{
${ }^{12}$ Certamente, esse próprio "passar do tempo" é construído dentro de um embate político e de uma perspectiva histórica e mereceria uma análise extensa, o que não é adequado para as considerações finais deste breve trabalho.
} 
terminação das atividades e das ações de cada um dos indivíduos, inclusive quanto ao papel social desempenhado por cada um.

Em relação à Ciência e ao conhecimento científico, o positivismo procurou resolver essa situação construindo e determinando um status de neutralidade. Durante muito tempo, essa confortável posição epistemológica foi naturalizada nos meios acadêmicos (e ainda é em várias disciplinas). Contudo, a realidade, a compreensão empírica das motivações do que está em jogo no fazer científico levaram a uma situação de questionamento dessa suposta neutralidade. Nessa perspectiva, vários autores da sociologia contemporânea fazem uma crítica ao positivismo e tentam romper com essa forma "neutra" de fazer Ciência, que negligencia os aspectos sociais e as possibilidades de ação (e de coerção) das estruturas em relação às tomadas de decisão dos agentes e dos grupos sociais.

Sendo assim, o objetivo deste artigo foi comentar brevemente a percepção de dois grandes estudiosos da teoria social, Bourdieu e Habermas. Eles apresentam aos pesquisadores sociais formas alternativas de pensar o fazer científico, associando a formação do conhecimento às suas consequências sociais. Com caminhos alternativos, quanto a vários aspectos excludentes, ambos os autores rejeitam a hipótese de que o saber é neutro. Pelo contrário, ambos assumem que há um processo de constituição sócio-histórico que acaba por definir e influenciar as condições atuais de produção do conhecimento, a qual está limitada a uma produção possível do conhecimento.

Ainda que Bourdieu coloque o cientista numa situação de contemplação de um "espetáculo", a partir da qual é possível perceber as determinações estruturais que levaram a cada situação, é sempre interessante refletir sobre como as ações e as possibilidades de ações são ou não escolhas e até que ponto elas o são. Habermas, por sua vez, propõe uma percepção a partir das escolhas humanas (as quais são limitadas) para conhecer o que está escondido além do conhecimento científico.

Por fim, é preciso chamar a atenção para o fato de que as hipóteses de programas naturalizados são insuficientes e inadequadas para o fazer científico crítico. É preciso atentar aos aspectos, seja pela abordagem bourdiana ou pela habermasiana, que estão permeando o pensar científico a cada momento.

\section{Referências}

1. BAUMGARTEN, M. Habermas e a emancipação: Rumo a democracia discursiva. Cadernos de Sociologia. Porto Alegre, v.10, p.137-178. Porto Alegre: PPGS, 1998.

2. BOURDIEU, P. Meditações Pascalianas. Rio do janeiro: Bertrand Brasil, 2001.

3. . As regras da arte: gênese e estrutura do campo literário. São Paulo: Companhia das Letras, 1996.

4. HABERMAS, J. Conhecimento e interesse. Rio de Janeiro: Zahar Editores, 1982.

5. OLIVEIRA, N. Rawls. Rio de janeiro: Jorge Zahar Ed., 2003.

6. OUTHWAITE, W. The Habermas Reader. Cambridge: Polity Press, 1996.

$7 . \quad$ Habermas: A Critical Introduction. Stanford: Stanford University Press, 1994. 